Original article

\title{
Effect of music therapy on ICU induced anxiety and physiological parameters among ICU patients: An experimental study in a tertiary care hospital of India
}

\author{
Jaskirat Kaur Chahal $^{\text {a }}$, Preksha Sharma ${ }^{\text {a, }}$, Sulena ${ }^{\text {b }}$, H.C.L. Rawat ${ }^{\text {a }}$ \\ ${ }^{\text {a }}$ University College of Nursing, Baba Farid University of Health Sciences, Faridkot, Punjab, India \\ b Department of Neurology, GGSMCH, Baba Farid University of Health Science, Faridkot, Punjab, India
}

\section{A R T I C L E I N F O}

\section{Keywords:}

Music

Therapy

Anxiety

Intensive care unit (ICU)

Physiological parameters

Patients

\begin{abstract}
A B S T R A C T
Background: Patients in intensive care unit (ICU) experience intense anxiety during their treatment which might also affect their physiological parameters.

Aim: Study aimed to assess the effectiveness of music therapy on ICU induced anxiety and physiological parameters among intensive care unit patients in a tertiary care hospital of India.

Methodology/Design: An experimental research approach with two groups pre-test post-test control design was used. 70 intensive care unit patients were randomized into two groups, experimental and conventional care group (35 in each group). The experimental group received 20 min tailored music therapy in addition to standard treatment thrice a day for continuous three days. In contrast, only standard care was provided to the other group. The socio-demographic sheet, clinical profile sheet, Zung Self Rating Anxiety Scale (SAS) and physiological parameter sheet was used to measure study parameters.

Results: Music therapy was highly effective $(\mathrm{t}=15.136(34) \mathrm{p}=<0.001)$ in reducing anxiety among experimental group subjects after the intervention whereas no change is seen in conventional care group on fourth day of the intervention. Similarly, music therapy was significantly effective in stabilizing physiological parameters among experimental group subjects during post test as compared to conventional care group.

Conclusion: Music therapy is a non-invasive, non-pharmaceutical and an efficient practice to abate the ICU induced anxiety among intensive care unit patients. It also possesses the ability to stabilize the main physiological parameters of intensive care unit patients. Study recommends the use of music therapy for ICU patients to stabilize their psychological and physiological parameter.
\end{abstract}

\section{Introduction}

The intensive care unit (ICU) is a distinct department in terms of the treatment modalities, physical appearance, technical equipment, and the nature of the sensitive environment. In case the vital functions of an individual depict hazardous health status, they need to receive treatment in an intensive care unit, to sustain vital functions by applying special remedial treatment practices. ${ }^{1}$ During the treatment process, patients in the intensive care unit experience numerous changes in their sleep pattern, comfort level, and psychological factors including anxiety. There are numerous precipitating factors which give rise to anxiety among them such as tracheostomy, endotracheal intubation and ventilation, fear of death, changes in the environment, and movement restriction because of invasive and non-invasive tools. ${ }^{2,3}$

According to American Music Therapy Association, Music therapy is the clinical and evidence-based use of music interventions to accomplish individualized goals within a therapeutic relationship by a credentialed professional who has completed an approved music therapy program. ${ }^{4}$ Music could be a global field that possesses the potential of making an equilibrium between mind, body, and soul. It has a promising effect not only on pain ${ }^{5}$ depression, ${ }^{6}$ but also has beneficial outcomes on the quality of life of sick or healthy people too. ${ }^{7}$

The effectiveness of music therapy as a non-pharmacological intervention is also determined among various other subjects too, such as

\footnotetext{
* Corresponding author.

E-mail addresses: jaskiratkaurchahal29@gmail.com (J.K. Chahal), prekshamaheshwari@gmail.com (P. Sharma), Neurology2019@ggsmch.org (Sulena), profhclrawat@gmail.com (H.C.L. Rawat).
} 
post-myocardial patients, ${ }^{8}$ pre-operative, intra-operative, and post-operative patients. ${ }^{9-11}$ Not only this but also have valuable outcomes in cancer patients, ${ }^{12}$ patients with neurological injuries, ${ }^{13}$ and even in burn patients. ${ }^{14}$ There are endless studies, illustrations, and examples available that highlight the beneficial findings of music therapy in the field of medical science.

Anxiety is a circumstance of apprehensiveness, inconclusiveness, or angst feeling resulting from the anticipation and preconception of the realistic or imaginary threatening event or situation. ${ }^{15}$ It may consist of behavioral, cognitive, emotional, and physical components. The exhibition of symptoms varies individually and gets aggravated by loneliness, manipulation in daily routine, exposure to the new or strange environment too. The disturbance in physiological and psychological functions can lead to an increase in mobility and mortality rates, therefore, its diagnosis and management are essential along with other curative measures.

Nowadays, in the field of Nursing, Music therapy is practiced as a complementary intervention that supports medicine and has accomplished as a non-invasive treatment method for patients deeming intensive care. It has been linked to cognitive, emotional, and psychosocial well-being, ${ }^{16}$ and also possesses beneficial results for spiritual anguish among patients. ${ }^{17}$ Collectively, the therapy acts as a boon for the sufferers by enhancing their capability to withstand or fight with the situation.

The valuable and salutary effects determined from the current study are to appraise the impact of music therapy on ICU induced anxiety and selective physiological parameters of ICU patients in order to strengthen the application of non-pharmacological or complementary therapies for the management process. It also deems to be a model for future studies in a similar field. This study is aimed to assess the effectiveness of music therapy on ICU induced anxiety and physiological parameters among intensive care unit patients in a tertiary care level hospital of India.

\section{Materials and methods}

A true experimental research approach with two group pre-test posttest research design was used for this study. The study groups consisted of experimental and conventional care group. The experimental group received $20 \mathrm{~min}$ music therapy thrice for continuous three days in addition to conventional care. In contrast, only routine care was provided to the other conventional group.

The Probability sampling technique with random allocation of subjects was practiced for sample selection after assessing their eligibility for present study using a random number generator from www. randomization.com. Initially, 76 patients were recruited/registered for study in beginning. Six were excluded due to not meeting inclusion criteria. Remaining sample of seventy subjects is randomly assigned to either the experimental group or the conventional care group (35 in each group). Experimental group was individually matched with the conventional group on socio demographic variable and clinical profile variables at baseline. Out of 70 patients selected for the study, all the patients completed the study without any dropout. The study subjects comprised of patients those who were admitted in intensive care units since 2 days at selected hospitals. Conscious, cooperative and available patients having age $>18$ years, admitted in critical care units since 2 days were selected for the study. Patients who were under sedation, unconscious and having contraindications related to music therapy due to certain conditions were excluded $(n=6)$ Fig. 1 .

The study was conducted on patients admitted in ICUs of a tertiary care hospital of north India. The intensive care units included under study were- Medical ICU, Surgical ICU, and Burn ICU. In these units, the patient population had a wide range of diagnosis such as diabetic ketoacidosis, cerebral palsy, chronic liver disease, renal failure, burn accident, and many more. Music Therapy was the independent variable whereas anxiety and physiological parameters of the ICU patients were dependent variable.

\section{Data collection tool}

A total of four research tools were used for the data collection which are as follows:

\subsection{Tool 1- Socio-demographic data sheet}

It is a self-structured tool and used to measure the socio-demographic profile of study subjects. It consists of eight items which are age, literacy

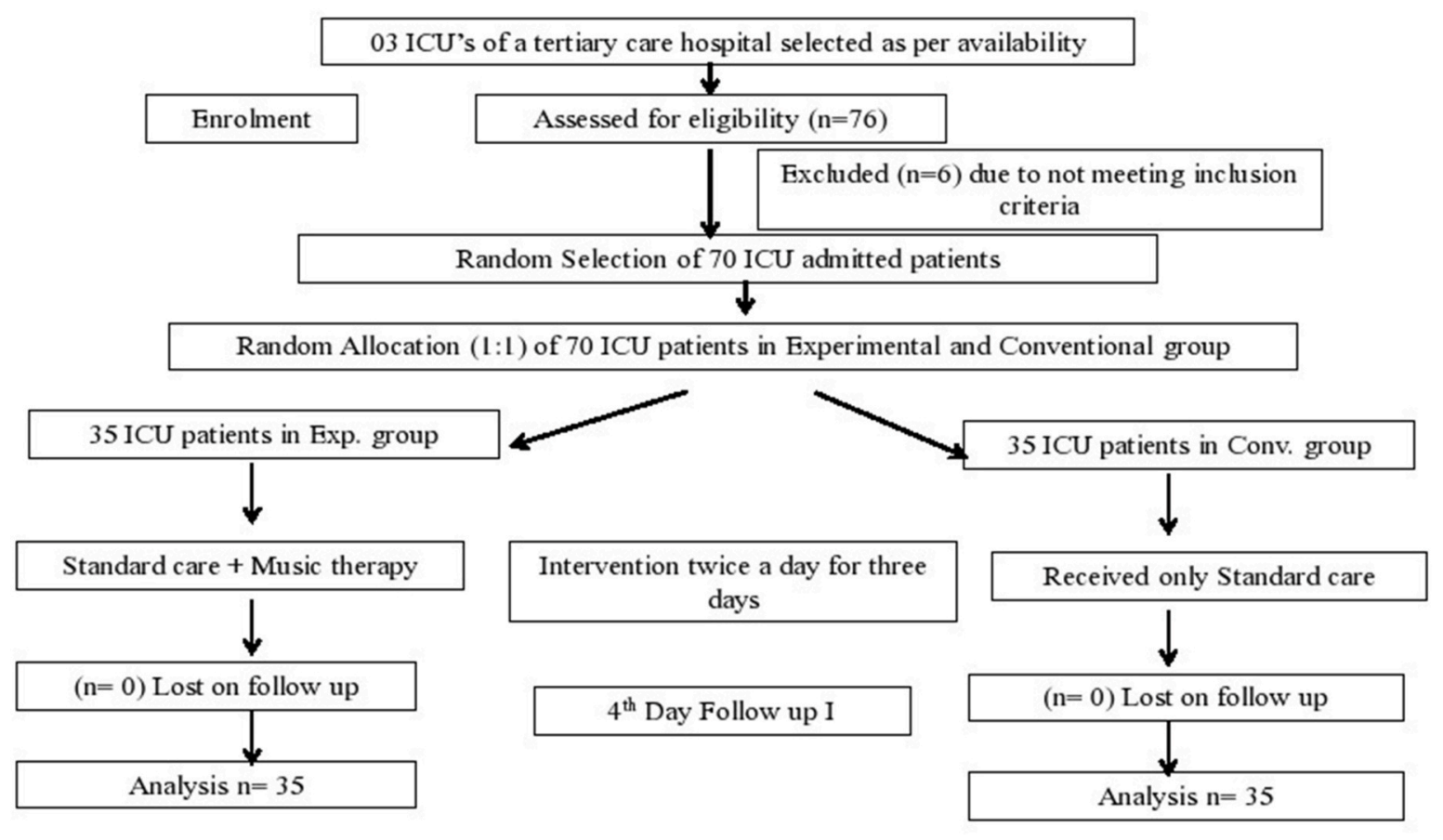

Fig. 1. CONSORT flow diagram. 
status, education of father, education of mother, family type, ordinal position, monthly income, and religion. The total administration time for this tool was approximately 3-5 min. Content validity of the tool was determined by experts in the field of psychiatry, psychology, and medicine, respectively. Reliability was done by the test-retest method and tool was found reliable $(r=1.0)$.

\subsection{Tool 2- Clinical data sheet}

It is a self-structured tool and used to measure the clinical information of participants. This consists of six clinical variables enlisted as history of previous hospitalisation, history of anti-anxiety treatment in past, duration of present hospitalisation, duration of intensive care unit admission and diagnosis of the subject. Participants were instructed to put a tick mark on appropriate response of each item. Total administration time for this tool was approximately $2 \mathrm{~min}$. Reliability was done by the test-retest method and tool was found reliable $(r=0.93)$.

\subsection{Tool 3 - Zung Self Rating Anxiety Scale (SAS)}

Zung Self-Rating Anxiety Scale (SAS) ${ }^{18}$ is a 20 -item, self-report questionnaire which measures the presence and magnitude of anxiety-based symptoms. The anxiety scale was constructed according to the DSM-II criteria for anxiety and still has the criteria listed in DSM-IV-TR (APA, 2000), giving it good content and face validity. ${ }^{18}$ It contains items that assess both physiological symptoms (e.g., muscle tremors, physical pain, and urinary frequency) and psychological (e.g., nervousness, fear, and mental disintegration) symptoms seen with anxiety. Each item is scored against a 4-point rating scale in relation to whether the person has experienced each specific symptom none or a little of the time (rating $=1$ ), some of the time (2), a good part of the time (3), or most or all of the time (4) during the last two weeks. Raw scores sum to 20-44 denoting normal anxiety levels, 45-59 denoting mild to moderate anxiety levels, 60-74 denoting marked to severe anxiety levels, and 75-80 indicating extreme anxiety levels. High score shows high anxiety. Reliability of the tools was established by test retest method and it was found $r=0.83$.

\subsection{Tool 4- Physiological parameter recording sheet}

It is self-structured tool to record and maintain the data of physiological parameters (including temperature, pulse rate, respiration rate, systolic blood pressure, diastolic blood pressure and oxygen saturation) of the intensive care unit patients. It is based on Macleod's Clinical Examination (13th Edition). ${ }^{19}$ It consists of body temperature rating and is measured in degree Fahrenheit $\left({ }^{0} \mathrm{~F}\right)$ by digital thermometer. The pulse rate and respiration rate were measured by the investigator manually in beats per minute and breaths per minute respectively. Systolic and diastolic blood pressure was measured by the same sphygmomanometer throughout the study in millimetre of mercury ( $\mathrm{mmHg}$ ). Oxygen saturation of the patients was measured by the same brand pulse oximeter in $\mathrm{spO}_{2}$. Normal reference values of all the selected physiological parameters is been given in box. The reliability of digital thermometer for temperature $(r=0.951)$, sphygmomanometer for systolic blood pressure $(r=0.985)$ and diastolic blood pressure $(r=0.933)$ and pulse oximeter for oxygen saturation was $(r=0.966)$.

Reference values for normal and abnormal physiological parameters.

\begin{tabular}{lll}
\hline Physiological parameters & $\begin{array}{l}\text { Range for } \\
\text { Normal }\end{array}$ & $\begin{array}{l}\text { Range for } \\
\text { Abnormal }\end{array}$ \\
\hline $\begin{array}{l}\text { Body temperature (degree of } \\
\text { Fahrenheit) }\end{array}$ & $98-99$ & $<98$ or $>99$ \\
$\begin{array}{l}\text { Pulse rate (beats per minute) } \\
\text { Respiration rate (per min) }\end{array}$ & $60-90$ & $<60$ or $>90$ \\
Systolic Blood pressure (in mmHg) & $16-24$ & $<16$ or $>24$ \\
Diastolic Blood pressure (in mmHg) & $110-139$ & $<110$ or $>139$ \\
Oxygen saturation (in percentage) & $70-89$ & $<70$ or $>89$ \\
\hline
\end{tabular}

Macleod's Clinical Examination (13th Edition).

\section{Intervention}

The interventional music therapy was provided to experimental group subjects only along with conventional care. Intervention was tailored by music therapist and had a mash-up of varying qualities of musical songs and instrumental music. Before and after completion of any song a soothing instrument was added to provide more flavour and variety to the intervention. Three different mashups of $20 \mathrm{~min}$ were composed under the direction of experts. The intervention was also validated by a designated music expert. The experimental group received $20 \mathrm{~min}$ music therapy thrice for continuous three days in addition to conventional care. Music was provided by Headphone connected to mp3 which had pre stored meshup of selected interventional music.

\section{Ethical consideration}

Formal ethical approval was acquired from the institutional ethical committee and permission was taken from the authorities in selected hospital settings (UCN/2019/230). The process of study was initiated in December 2018 and completed in April 2019.

\section{Data analysis}

In descriptive statistics; mean, percentages, and standard deviation were applied for analyzing the distribution of subjects according to their socio-demographic and clinical characteristics. Whereas, in inferential statistics, paired $t$-test, independent $t$-test and chi-square test were computed by SPSS 20.0 statistical package. The $\mathrm{p}$ value at $<0.05$ was considered as statistically significant.

\section{Results}

Table 1 illustrate the comparison of socio-demographic characteristics between experimental and conventional care group at baseline which shows that both the groups were comparable and homogenous before giving intervention with regards to these characteristics.

Table 2 explains the comparison of clinical characteristics between experimental and conventional care group at baseline which shows that both the groups were comparable and homogenous before giving intervention with regards to these clinical characteristics. Similarly, baseline anxiety was compared between experimental and conventional care group which shows that both the groups were comparable and homogenous before giving intervention with regards to anxiety (Table 3).

Table 4 explains the comparison of selected physiological parameters between experimental and conventional care group at baseline which shows that both the groups were comparable and homogenous before giving intervention with regards to these selected physiological parameters.

As shown in Table 5, music therapy was highly effective $(t=15.136$ (34) $\mathrm{p}=<0.001$ ) in reducing anxiety among experimental group subjects after the intervention. There was no significant change in anxiety score in conventional care group where no intervention was give except routine care.

As shown in Table 6, music therapy was highly effective $(\mathrm{t}=12.57$ (68) $\mathrm{p}=<0.001$ ) in reducing anxiety among experimental group subjects during post test as compared to conventional care group where no intervention was given except conventional care. Similarly, music therapy was significantly effective in stabilizing physiological parameters among experimental group subjects during post test as compared to conventional care group where no intervention was given except conventional care (Table 7). 
Table 1

Comparison of experimental and conventional care group at baseline with regards to socio-demographic characteristics. $(\mathrm{N}=70$.)

\begin{tabular}{|c|c|c|c|c|c|}
\hline Variable & Category & Experimental group f (\%) & Conventional care group f (\%) & $\chi^{2}(\mathrm{df})$ & p-value \\
\hline \multirow[t]{6}{*}{ Age (in years) } & $18-25$ & $3(8.6)$ & $0(0)$ & $9.19(5)$ & $0.101^{\mathrm{NS}}$ \\
\hline & $26-30$ & $3(8.6)$ & $2(5.7)$ & & \\
\hline & $31-35$ & $6(17.1)$ & $1(2.9)$ & & \\
\hline & $36-40$ & $3(8.6)$ & $7(20.0)$ & & \\
\hline & $41-45$ & $5(14.3)$ & $8(22.9)$ & & \\
\hline & $\geq 46$ years & $15(42.86)$ & $17(48.57)$ & & \\
\hline \multirow[t]{2}{*}{ Gender } & Male & $18(51.43)$ & $20(57.14)$ & $0.23(1)$ & $0.631^{\mathrm{NS}}$ \\
\hline & Female & $17(48.57)$ & $15(42.86)$ & & \\
\hline \multirow[t]{4}{*}{ Education } & Illiterate & $11(31.43)$ & $12(34.29)$ & $3.65(3)$ & $0.301^{\mathrm{NS}}$ \\
\hline & Primary ed. & $16(45.71)$ & $9(25.71)$ & & \\
\hline & Graduate & $7(20)$ & $12(34.29)$ & & \\
\hline & Post-graduate & $1(2.86)$ & $2(5.71)$ & & \\
\hline \multirow[t]{3}{*}{ Family Income } & Lower class (Rs. $10,000-30,000$ ) & $20(57.14)$ & $14(40)$ & $2.07(2)$ & $0.354^{\mathrm{NS}}$ \\
\hline & Middle class (Rs. $30,000-50,000$ ) & $11(31.43)$ & $15(42.86)$ & & \\
\hline & Upper class $(>50,000)$ & $4(11.43)$ & $6(17.14)$ & & \\
\hline \multirow[t]{5}{*}{ Occupation } & Student & $2(5.71)$ & $1(2.86)$ & $0.80(4)$ & $0.938^{\mathrm{NS}}$ \\
\hline & Unemployed & $15(42.86)$ & $13(37.14)$ & & \\
\hline & Self-employed & $12(34.29)$ & $13(37.14)$ & & \\
\hline & Govt. employee & $3(8.57)$ & $4(11.43)$ & & \\
\hline & Private employee & $3(8.57)$ & $4(11.43)$ & & \\
\hline \multirow[t]{3}{*}{ Marital Status } & Married & $29(82.86)$ & $31(88.57)$ & $4.20(4)$ & $0.379^{\mathrm{NS}}$ \\
\hline & Unmarried & $4(11.43)$ & $1(2.86)$ & & \\
\hline & Divorcee/widow/separated & $2(5.72)$ & $3(8.6)$ & & \\
\hline \multirow[t]{4}{*}{ Religion } & Sikh & $20(57.14)$ & $19(54.29)$ & $1.69(3)$ & $0.639^{\mathrm{NS}}$ \\
\hline & Hindu & $12(34.29)$ & $15(42.86)$ & & \\
\hline & Christian & $1(2.86)$ & $0(0)$ & & \\
\hline & Muslim & $2(5.71)$ & $1(2.86)$ & & \\
\hline \multirow[t]{3}{*}{ Type of Family } & Joint & $19(54.29)$ & $20(57.14)$ & $1.36(2)$ & $0.507^{\mathrm{NS}}$ \\
\hline & Nuclear & $15(42.86)$ & $12(34.29)$ & & \\
\hline & Extended & $1(2.86)$ & $3(8.57)$ & & \\
\hline
\end{tabular}

Level of significance at $\mathrm{p}<0.05$.

NS $=$ Non significant.

Table 2

Comparison of experimental and conventional care group at baseline with regards to clinical characteristics. $(\mathrm{N}=70)$.

\begin{tabular}{|c|c|c|c|c|c|}
\hline \multirow[t]{2}{*}{ Variables under Study } & \multirow[t]{2}{*}{ Category } & \multirow{2}{*}{$\frac{\text { Experimental group }}{\mathrm{f}(\%)}$} & \multirow{2}{*}{$\frac{\text { Conventional care group }}{\mathrm{f}(\%)}$} & \multirow[t]{2}{*}{$\chi^{2 / \mathrm{df}}$} & \multirow[t]{2}{*}{$\mathrm{p}$ value } \\
\hline & & & & & \\
\hline \multirow[t]{2}{*}{ History of hospitalisation in past } & Yes & $17(48.57)$ & $19(54.29)$ & \multirow[t]{2}{*}{$0.23(1)$} & \multirow[t]{2}{*}{$0.632^{\mathrm{NS}}$} \\
\hline & No & $18(51.43)$ & $16(45.71)$ & & \\
\hline \multirow[t]{2}{*}{ History of receiving any treatment for anxiety in past } & Yes & $12(34.29)$ & $17(48.57)$ & \multirow[t]{2}{*}{$1.47(1)$} & \multirow[t]{2}{*}{$0.225^{\mathrm{NS}}$} \\
\hline & No & $23(65.71)$ & $18(51.43)$ & & \\
\hline \multirow[t]{4}{*}{ Duration of present hospital admission } & 2 Days & $4(11.43)$ & $6(17.14)$ & \multirow[t]{4}{*}{$2.08(3)$} & \multirow[t]{4}{*}{$0.555^{\mathrm{NS}}$} \\
\hline & 3-4 Days & $14(40)$ & $10(28.57)$ & & \\
\hline & 5-7 Days & $11(31.43)$ & $15(42.86)$ & & \\
\hline & >7 Days & $6(17.14)$ & $4(11.43)$ & & \\
\hline \multirow[t]{4}{*}{ Duration of trans-in to I.C.U } & 2 Days & $18(51.43)$ & $16(45.71)$ & \multirow[t]{4}{*}{$0.72(3)$} & \multirow[t]{4}{*}{$0.867^{\mathrm{NS}}$} \\
\hline & 3-4 Days & $10(28.57)$ & $12(34.29)$ & & \\
\hline & 5-7 Days & $6(17.14)$ & $5(14.29)$ & & \\
\hline & >7 Days & $1(2.86)$ & $2(5.71)$ & & \\
\hline \multirow[t]{4}{*}{ Diagnosis } & Neuro/Surgery & $14(40)$ & $12(34.29)$ & \multirow[t]{4}{*}{$1.15(3)$} & \multirow[t]{4}{*}{$0.764^{\mathrm{NS}}$} \\
\hline & Cardio & $11(31.43)$ & $9(25.71)$ & & \\
\hline & Medicine & $8(22.86)$ & $12(34.29)$ & & \\
\hline & Burn & $2(5.71)$ & $2(5.71)$ & & \\
\hline
\end{tabular}

Level of significance at $\mathrm{p}<0.05$.

NS $=$ Non significant.

Table 3

Comparison of mean anxiety scores between experimental and conventional care group at baseline $(\mathrm{N}=70)$.

\begin{tabular}{|c|c|c|c|c|c|}
\hline \multirow[t]{2}{*}{ Outcome variables } & \multicolumn{2}{|l|}{ Group } & \multirow[t]{2}{*}{$t$-test } & \multirow[t]{2}{*}{ df } & \multirow[t]{2}{*}{$\mathrm{p}$ value } \\
\hline & $\begin{array}{l}\text { 'Experimental group' }(\mathrm{n}=35) \\
\text { Mean (SD) }\end{array}$ & $\begin{array}{l}\text { 'Conventional care group' }(\mathrm{n}=35) \\
\text { Mean (SD) }\end{array}$ & & & \\
\hline Anxiety & $57.829(3.04)$ & $58.057(2.96)$ & 0.32 & 68 & 0.751 \\
\hline
\end{tabular}

Level of significance at $\mathrm{p}<0.05$ 
Table 4

Comparison of selected physiological parameters in experimental and conventional care group at baseline $(\mathrm{N}=70)$.

\begin{tabular}{|c|c|c|c|c|c|}
\hline Physiological Parameters & Category & Experimental group (35) & Conventional care group (35) & $\chi 2$ value (df) & $\mathrm{p}$ value \\
\hline \multirow[t]{2}{*}{ Temperature } & Normal & 17 & 15 & $0.23(1)$ & $0.631^{\mathrm{NS}}$ \\
\hline & Abnormal & 18 & 20 & & \\
\hline \multirow[t]{2}{*}{ Pulse rate } & Normal & 15 & 13 & $0.24(1)$ & $0.625^{\mathrm{NS}}$ \\
\hline & Abnormal & 20 & 22 & & \\
\hline \multirow[t]{2}{*}{ Respiration rate } & Normal & 17 & 15 & $0.23(1)$ & $0.631^{\mathrm{NS}}$ \\
\hline & Abnormal & 18 & 20 & & \\
\hline \multirow[t]{2}{*}{ Systolic blood pressure } & Normal & 11 & 12 & $0.06(1)$ & $0.799^{\mathrm{NS}}$ \\
\hline & Abnormal & 24 & 23 & & \\
\hline \multirow[t]{2}{*}{ Diastolic blood pressure } & Normal & 16 & 13 & $0.53(1)$ & $0.466^{\mathrm{NS}}$ \\
\hline & Abnormal & 19 & 22 & & \\
\hline \multirow[t]{2}{*}{ Oxygen saturation } & Normal & 28 & 23 & $1.81(1)$ & $0.178^{\mathrm{NS}}$ \\
\hline & Abnormal & 7 & 12 & & \\
\hline
\end{tabular}

Level of significance at $\mathrm{p}<0.05$.

NS $=$ Non significant

Table 5

Comparison of baseline and post-test mean score for anxiety in experimental and control group $(\mathrm{N}=70)$.

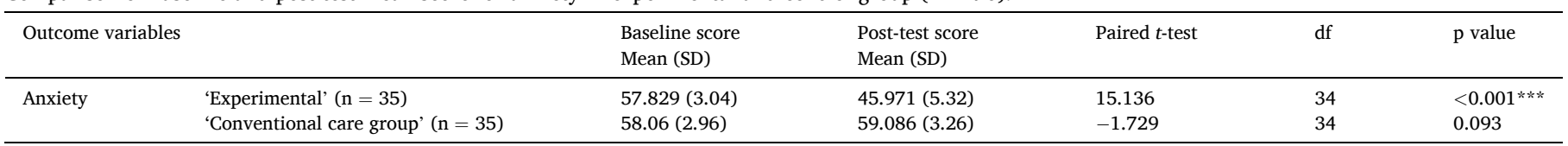

$* * *$ Highly significant at level of $<0.001$.

Table 6

Comparison of mean anxiety scores between experimental and conventional group at post test $(\mathrm{N}=70)$.

\begin{tabular}{|c|c|c|c|c|c|}
\hline \multirow[t]{2}{*}{ Outcome variables } & \multicolumn{2}{|l|}{ Group } & \multirow[t]{2}{*}{$t$-test } & \multirow[t]{2}{*}{$\mathrm{df}$} & \multirow[t]{2}{*}{$\mathrm{p}$ value } \\
\hline & $\begin{array}{l}\text { 'Experimental' }(\mathrm{n}=35) \\
\text { Mean (SD) }\end{array}$ & $\begin{array}{l}\text { 'conventional' }(\mathrm{n}=35) \\
\text { Mean (SD) }\end{array}$ & & & \\
\hline Anxiety & $45.97(5.2)$ & $59.086(3.27)$ & 12.57 & 68 & $<0.001^{* * *}$ \\
\hline
\end{tabular}

$* * *$ Highly significant at level of $<0.001$.

Table 7

Comparison of experimental and conventional care group at post-test (Day 4) with regards to selected physiological parameters. ( $\mathrm{N}=70$ ).

\begin{tabular}{|c|c|c|c|c|c|}
\hline Physiological Parameters & Category & Experimental group $(\mathrm{n}=35) \mathrm{f}$ & Conventional care group $(n=35) f$ & $\chi 2$ value (df) & $\mathrm{p}$ value \\
\hline \multirow[t]{2}{*}{ Temperature } & Normal & 26 & 15 & $7.12(1)$ & $0.0075^{* *}$ \\
\hline & Abnormal & 9 & 20 & & \\
\hline \multirow[t]{2}{*}{ Pulse rate } & Normal & 25 & 12 & $9.68(1)$ & $0.0017 * *$ \\
\hline & Abnormal & 10 & 23 & & \\
\hline \multirow[t]{2}{*}{ Respiration rate } & Normal & 25 & 13 & $8.29(1)$ & $0.0039 * *$ \\
\hline & Abnormal & 10 & 22 & & \\
\hline \multirow[t]{2}{*}{ Systolic B.P. } & Normal & 27 & 15 & $8.57(1)$ & $0.0033^{* *}$ \\
\hline & Abnormal & 8 & 20 & & \\
\hline \multirow[t]{2}{*}{ Diastolic B.P. } & Normal & 28 & 15 & $10.19(1)$ & $0.0013^{* *}$ \\
\hline & Abnormal & 7 & 20 & & \\
\hline \multirow[t]{2}{*}{ Oxygen saturation } & Normal & 33 & 24 & $7.65(1)$ & $0.0056^{* *}$ \\
\hline & Abnormal & 2 & 11 & & \\
\hline
\end{tabular}

Highly significant at $\mathrm{p}<0.01 * *$.

\section{Discussion}

Study found that mild to marked severe anxiety was present among all of the subjects due to ICU admission before intervention. The finding is supported by a research study which concluded that $85 \%$ of ICU patients experience anxiety. ${ }^{20}$ It was found that majority of them were male and belonged to age group of 46 years and above. The comparison of experimental and conventional care group at baseline with regards to socio-demographic and clinical characteristics were found to be non-significant at $\mathrm{p}$ value $<0.05$. Furthermore, a study by (Castillo MI, Cooke $\mathrm{M}$ et. al. 2016) ${ }^{21}$ also enumerated that $82 \%$ of patients experienced state anxiety and $57 \%$ reported moderate to severe level of anxiety at least once during their stay in intensive care units.

Present study reported that music therapy was highly effective in reducing anxiety and stabilizing physiological parameters among experimental group subjects during post test as compared to conventional care group where no intervention was given except routine care. This finding is in line with available studies. Golino AJ et al. (2019) ${ }^{22}$ demonstrated that after the music intervention, significant changes were found in respiratory rate (mean difference, 3.7), heart rate (5.9), and anxiety levels $(2.7)$ at $(\mathrm{p}<0.001)$. Hence, the present study disseminates and reproves the fact that music has beneficial impact on physiological parameters of intensive care unit patients. The findings are also supported by (Hatice C et.al. 2015) ${ }^{23}$ who conducted an experimental study on ICU patients diagnosed with cerebro-vascular accident, in order to determine the effect of music on anxiety, comfort and pain. Another studies also supported the study findings. ${ }^{24,25}$

One more study has favourable assistance to the present study 
(Hatice C et.al. 2015). ${ }^{23}$ concluded that music has beneficial outcomes on physiological parameters as the mean score of systolic blood pressure was $142 \mathrm{~mm} / \mathrm{Hg}$ at the beginning and reduced to $138 \mathrm{~mm} / \mathrm{Hg}$ after they received music.

\section{Conclusion}

Present study concluded that music therapy was highly effective in reducing ICU induced anxiety and stabilizing physiological parameters among patient who are admitted in ICU's during post test as compared to conventional care group where no intervention was given except routine care. Therefore, it can be added as a non-pharmaceutical intervention to manage ICU induced anxiety and physiological parameters of intensive care unit patients. Multiple studies suggested that this music has significant impact on the cardiovascular system and influences significantly heart rate, blood pressure and other physiological parameters as well. This kind of music is effective and can be used as an effective intervention in ICU admitted patients.

\section{Limitation}

Present study is limited to small sample size (i.e. 70 only) making it difficult to generalize the findings. It is a study in which effectiveness of music therapy on ICU induced anxiety and physiological parameters is assessed after shorter time period i.e. 4 days. Patients with only one study setting were included in the study.

\section{Financial support and sponsorship}

Nil.

\section{Ethical approval of research}

This study was approved by the Institutional Research and Ethical Committee (UCN/2019/230).

\section{Declaration of competing interest}

There are no conflicts of interest.

\section{Acknowledgement}

Nil.

\section{References}

1 Arslan S, Ozer N. Complementary treatments for emotional problems of patients hospitalized in intensive care unit. Journal Anatolia Nursing and Health Science. 2010; 13(2):68-75.
2 Tracy MF, Chlan Linda, Abbey Staugaitis. Perceptions of patients and families who received a music intervention during mechanical ventilation. Music Medicine. 2015;7: 54-58.

3 Gaurav Sharma B, Maben EVS, Kotian MS, et al. Psychological evaluation of patients in critical care/intensive care unit and patients admitted in wards. J Clin Diagn Res. 2014:8(12):WC01-WC03.

4 Official definition of the American Music Therapy Association [AMTA] http://www. musictherapy.org/about/quotes/.

5 Kaliyaperumal Raji, Gowri Subash Jaya. Effect of Music therapy for patients with cancer pain. Int. J. Biol. Med. Res. 2010;1(3):79-81.

6 Erkkilä Jaakko, Punkanen Marko, Fachner Jorg, et al. Individual music therapy for depression: randomised controlled trial. Br J Psychiatr. 2011;199(2):132-139.

7 Carme Sole, Mercadal-Brotons Melissa, Galati Adrián, et al. Effects of group music therapy on quality of life, affect, and participation in people with varying levels of dementia. J Music Ther. 2014;51(1):103-125.

8 White JM. Effects of relaxing music on cardiac autonomic balance and anxiety after acute myocardial infarction. Am J Crit Care. 1999;8(4):220-230.

$9 \mathrm{Ni} \mathrm{CH}$, Tsai WH, Lee LM, et al. Minimising preoperative anxiety with music for day surgery patients - a randomised clinical trial. J Clin Nurs. 2012;21:620-625.

10 Bae I, Lim HM, Hur MH, et al. Intra-operative music listening for anxiety, the BIS index, and the vital signs of patients undergoing regional anaesthesia. $J$ Complement Therapies Med. 2014;22:251-257.

11 Ames Nancy, Yang Li, Frey M, et al. Music listening among postoperative patients in the intensive care unit: a randomized controlled trial with mixed-methods analysis. J Integrative Med Insights. 2017. https://doi.org/10.1177/1178633717716455. Available from.

12 Jasemi Madineh, Aazami Sanaz, Zabihi Roghaieh Esmaili. The effects of music therapy on anxiety and depression of cancer patients. Indian J Palliat Care. 2016;22 (4):455-458.

13 Raglio Alfredo, Attardo Lapo, Gontero Giulia, et al. Effects of music and music therapy on mood in neurological patients. World J Psychiatry Mar. 2015;5(1):68-78.

14 Naderi F, Aghaei A, Mohammad-zadeh M, Nazemi S, Salmani F, Rashvand M. The effects of music therapy on pain threshold, anxiety, distress response and hemodynamic parameters during dressing changes in burn patients. Horizon Med Sci J. 2014;20(1):63-68. http://hms.gmu.ac.ir/article-1-1885-en.html.

15 Richards JC, Bertram S. Anxiety sensitivity, state and trait anxiety, and perception of change in sympathetic nervous system arousal. J Anxiety Disord. 2000;14(4): 413-427.

16 Fujioka T, Dawson DR, Wright R, et al. The effects of music-supported therapy on motor, cognitive, and psychosocial functions in chronic stroke. Ann N Y Acad Sci. 2018. https://doi.org/10.1111/nyas.13706. Available from.

17 Mcclean Stuart, Bunt Leslie, Daykin Norma. The healing and spiritual properties of music therapy at a cancer care center. J Alternative Compl Med. 2012;18(4):402-407.

18 Zung WWK. A rating instrument for anxiety disorders. Psychosomatics. 1971;12(6): $371-379$.

19 Douglas G, Nicol F, Robertson C. Macleod's Clinical Examination. London: Elsevier Health Sciences UK; 2013.

20 McKinley Sharon, Stein-Parbury Jane, Lovas Judy, et al. Assessment of anxiety in intensive care patient by using the Faces Anxiety Scale. Am J Crit Care. 2004;13(2): $146-152$.

21 Castillo MI, Cooke M, Macfarlane B, Aitken LM. Factors associated with anxiety in critically ill patients: a prospective observational cohort study. Int J Nurs Stud. 2016 Aug;60:225-233.

22 Golino AJ, Leone R, Gollenberg A, et al. Impact of an active music therapy intervention on intensive care patients. Am J Crit Care. 2019;28(1):48-55.

23 Ciftci H, Otzunc G. The effect of music therapy on comfort,anxiety and pain in the intensive nursing care unit; A case in Turkey. Int J Caring Sci. 2015;8, 594-63.

24 Gullick JG, Kwan XX. Patient-directed music therapy reduces anxiety and sedation exposure in mechanically-ventilated patients: a research critique. Aust Crit Care. 2015;28:103-105.

25 Ghodela AK, Singh V, Kaushik N, Maheshwari SK. Effectiveness of progressive muscle relaxation therapy on anxiety and depression: a pre-experimental study on elderly people of old age homes. Indian J Psy Nsg. 2019;16(2):56-60. 